Check for updates

Cite this: RSC Adv., 2019, 9, 31583

Received 29th August 2019

Accepted 24th September 2019

DOI: $10.1039 / c 9 r a 06857 k$

rsc.li/rsc-advances

\section{Curing kinetics of phenolphthalein based polyphosphazene towards thermal stability and flame retardancy of polybenzoxazine $\uparrow$}

\author{
Ling Zhao, ${ }^{a}$ Chunxia Zhao, (D) *a Min Wu, ${ }^{a}$ Yuntao Li, ${ }^{\star a b}$ Hui Li, ${ }^{a}$ Dong Xiang ${ }^{a}$ \\ and Cuicui Guo ${ }^{a}$
}

\begin{abstract}
Phenolphthalein type polyphosphazene (PZPT) microspheres were synthesized by an ultrasound assisted precipitation polymerization method, and their structures were confirmed by scanning electron microscopy (SEM) and Fourier transform infrared (FTIR) spectroscopy. Benzoxazine/PZPT (Ba/PZPT) hybrid materials were fabricated and cured to prepare polybenzoxazine/PZPT (PBa/PZPT) composites. The effects of PZPT microspheres on the curing kinetics and behaviors of Ba were systematically analyzed and supported by differential scanning calorimetry (DSC) and in situ FTIR. The thermogravimetric (TGA) results demonstrated good thermal stability of the PBa composites incorporating PZPT. The peak of heat release rate and total heat release values of PBa/PZPT-5\% composites obviously deceased by $57.8 \%$ and $17.3 \%$ compared to those of the pristine PBa. Moreover, the smoke released from the PZPT/PBa system significantly reduced with the loading of microspheres. Finally, the dynamical mechanical analysis results demonstrated that the $T_{\mathrm{g}}$ of PBa flame retardant composites was approximately $210^{\circ} \mathrm{C}$, not affecting further applications of PBa composites.
\end{abstract}

\section{Introduction}

Benzoxazine, as a novel type of phenolic resin, features a benzene ring comprising a nitrogen and heterocyclic sixmembered oxazine ring. ${ }^{1}$ Polybenzoxazine can be easily produced by the ring-opening polymerization of benzoxazine without the need for hardeners or a catalyst. ${ }^{2}$ Therefore, polybenzoxazine is thought to be a promising candidate in aerospace, adhesives, electronics, and other fields, ${ }^{3}$ owing to its extraordinary properties such as (i) near-zero shrinkage during curing, (ii) a high glass transition temperature, (iii) excellent mechanical properties, (iv) low water absorption, (v) high charring yield, (vi) extremely good molecular design flexibility, and (vii) low dielectric properties. ${ }^{4}$

Nevertheless, bisphenol A type polybenzoxazine (PBa) also has some disadvantages such as high curing temperature $(>200$ ${ }^{\circ} \mathrm{C}$ ) and the lower limited oxygen index (22), restricting their further development in industrial applications. ${ }^{5}$ Currently, more and more studies have been focused on decreasing the curing temperature of $\mathrm{PBa}$. One approach is to incorporate the special functional groups such as carboxyl, hydroxyl, formyl,

${ }^{a}$ School of Materials and Engineering, Southwest Petroleum University, Chengdu 610500, China.E-mail:yuntaoli@swpu.edu.cn; polychem2011@hotmail.com

${ }^{b}$ State Key Lab of Oil and Gas Reservoir Geology and Exploitation, Southwest Petroleum University, Chengdu 610050, China

$\dagger$ Electronic supplementary information (ESI) available. See DOI: 10.1039/c9ra06857k phenolic hydroxyl, and cyanate ester into the benzoxazine monomer. ${ }^{6}$ Other approach involves the use of catalyst or initiators including Lewis acids, bifunctional catalysts, phosphonic acids and sulfonic acids, and basic compounds such as amines and imidazoles. ${ }^{7}$ These catalysts or initiators can effectively deteriorate the curing temperature regardless of the catalytic mechanism. Numerous reactions occur simultaneously during the curing process, making it a relatively complicated process. ${ }^{8}$ However, the performance of $\mathrm{PBa}$ to a large extent depends on the kinetics of the curing reaction, especially with respect to the degree of cure and curing conditions. Therefore, in order to make better use of the benzoxazine resin improving the performance of the resulting product, and wide applicability, it is necessary to understand the nature of the curing process, the structure of the cured material, and the change in its kinetic parameters. ${ }^{9}$

The phenolphthalein-containing polymers have been extensively studied for several years. For example, Yang et al. synthesized a pure benzoxazine (Boz-BP) using phenolphthalein as raw material through Mannich reaction. Due to forming an additional hydrogen bond between the carbonyl group and the hydroxyl group on the phenylhydrazine structure, Boz-BP-based polymer $(\mathrm{P}(\mathrm{Boz}-\mathrm{BP}))$ have a higher glass transition temperature, better thermal stability, good dimensional stability and flame retardant properties. ${ }^{10}$ Zhao et al. reported that cyanate ester (CE) resins were simply modified through melt-blending with a phenolphthalein type polyarylether sulfone (cPES). The cPES/ $\mathrm{CE}$ resins cPES/CE resins improved integrated performances 
including impact strength, flexural properties, dielectric properties and thermal-stability compared with CE resin. ${ }^{11}$

Phosphate-nitrogen flame retardants, as a highly efficient and environmentally friendly and newly flame retardant, are widely available alternative feedstock. ${ }^{12}$ These are also called intumescent flame retardants. ${ }^{13}$ Hexachlorocyclotriphosphazene (HCCP) consists of alternating $\mathrm{N}$ and $\mathrm{P}$ atoms and is an environmentally friendly flame retardant material. ${ }^{12 a, 14}$ The chlorine element in its structure can be substituted and decomposed into small molecules with less environmental impact and has a higher nitrogen and phosphorus content, thus exhibiting better flame retardant properties. ${ }^{15}$ With increasing understanding of cyclophosphazene compounds, many new cyclophosphazene flame retardants have been developed to replace traditional halogens and other halogenfree flame retardants for thermoset and thermoplastic materials to meet their resistance for flammability, thermal performance, and other desired properties. ${ }^{16}$

The introduction of PZPT microspheres in the thermosetting resin benzoxazine resin will inevitably affect the curing behavior of benzoxazine resin and combustion properties. In this study, one type of polybenzoxazine with good flame retardant and lower curing temperature was prepared using PZPT microspheres in benzoxazine by melt blending. To investigate this reaction in detail, three types of $\mathrm{PBa}$ with different PZPT contents (PBa/PZPT-1\%, PBa/PZPT-3\%, and $\mathrm{PBa} / \mathrm{PZPT}-5 \%$ ) were explored, and the curing behavior, thermal stability, flame retardancy, and thermomechanical properties of obtained polybenzoxazine were investigated by different scanning calorimetry (DSC), in situ Fourier transform infrared (in situ FTIR) spectroscopy, thermogravimetric analysis (TGA), cone calorimeter test (CONE), and dynamic mechanical analysis (DMA).

\section{Experimental}

\subsection{Materials}

Phenolphthalein (PT) and HCCP was supplied from Chengdu Best Reagents Co., Ltd. (China). Bisphenol A-based benzoxazine (Ba) was provided by Sichuan Tiance Jucai Technology Co., Ltd. Acetonitrile, trimethylamine (TEA), ethanol, and acetone were purchased from Chengdu Kelong Chemical Reagent Factory (China).

\subsection{Synthesis of PZPT}

PZPT microspheres were prepared by ultrasound-assisted precipitation polymerization. First, $0.4 \mathrm{~g}$ (1.15 mmol) HCCP and $2.2 \mathrm{~g}$ (3.45 mmol) PT were dissolved in $100 \mathrm{~mL}$ acetonitrile in a $250 \mathrm{~mL}$ single-mouth flask. Then, the solution was ultrasonicated $(250 \mathrm{~W}, 40 \mathrm{kHz})$ for $10 \mathrm{~min}$, followed by adding $4 \mathrm{~mL}$ TEA. The flask was sealed immediately, and heated at $50{ }^{\circ} \mathrm{C}$ for $4 \mathrm{~h}$, successfully affording white precise PZPT microspheres. Finally, the product was washed several times with ethanol, acetone, and deionized water. Scheme 1 shows the reaction route for the preparation of PZPT.

\subsection{Preparation of $\mathrm{PBa} / \mathrm{PZPT}$ composites}

$4 \mathrm{~g}$ PZPT and $76 \mathrm{~g}$ Ba were distributed in $40 \mathrm{~mL}$ acetone in threenecked flask under ultrasound at room temperature. Then, the acetone was removed by gradient heating in the range 60$120{ }^{\circ} \mathrm{C}$ under reduced pressure, affording pure $\mathrm{Ba} / \mathrm{PZPT}$ product. Next, the mixture was poured into a glass mold with a release agent and preheated for curing at $180{ }^{\circ} \mathrm{C} / 2 \mathrm{~h}$, followed by $200{ }^{\circ} \mathrm{C} / 2 \mathrm{~h}$. The cured product was labeled as PBa/PZPT- $5 \%$. $\mathrm{PBa}, \mathrm{PBa} / \mathrm{PZPT}-1 \%$ and $\mathrm{PBa} / \mathrm{PZPT}-3 \%$ were prepared by the similar process.

\subsection{Characterization}

The surface functional groups of the microspheres were investigated by FTIR using a Nicolet 6700 spectrometer (Thermo Electron Co., USA). TGA was carried out using a STA 6000 (PerkinElmer, USA) under a nitrogen atmosphere at a flow rate of $50 \mathrm{~mL} \mathrm{~min}{ }^{-1}$ and a heating rate of $20^{\circ} \mathrm{C} \mathrm{min}{ }^{-1}$ from $40{ }^{\circ} \mathrm{C}$ to $800{ }^{\circ} \mathrm{C}$. The morphology and elemental analysis of the microspheres were carried out by scanning electron microscopy (SEM) using a ZEISS EV0 MA15 SEM from Carl Zeiss Micro Image Co., Ltd. The non-isothermal DSC curing reaction of the $\mathrm{Ba}$ and $\mathrm{Ba} / \mathrm{PZPT}$ mixture was monitored using a Q20 equipment (TA instruments) from $40{ }^{\circ} \mathrm{C}$ to $350{ }^{\circ} \mathrm{C}$ at different heating rates of $5,10,15$, and $20^{\circ} \mathrm{C} \min ^{-1}$. In situ FTIR spectroscopy was conducted using a frontier PerkinElmer FTIR spectrometer, and spectra were recorded every $18 \mathrm{~s}$ from 100 to $250{ }^{\circ} \mathrm{C}$ at a heating rate of $2.5^{\circ} \mathrm{C} \mathrm{min}^{-1}$. DMA was carried out using a Q800 analyzer (TA Instruments) from 40 to $300{ }^{\circ} \mathrm{C}$ at a heating rate of $5{ }^{\circ} \mathrm{C}$ per step and a frequency of $1 \mathrm{~Hz}$ in the air. In the three-point bending mode, samples with $40 \times 10 \times 3.2 \mathrm{~mm}^{3}$ dimension were used.

\section{Results and discussion}

\subsection{Characterization of PZPT microspheres}

The important structural features of PT, HCCP, and PZPT were observed by FTIR, as shown in Fig. 1 . In the case PZPT, the stretching vibration peaks at 1607 and $1503 \mathrm{~cm}^{-1}$ are attributed to the aromatic $\mathrm{C}=\mathrm{C}$ group absorption of the phenol in the $\mathrm{PT}$ units. Moreover, the apparent peak in the range 3100$3000 \mathrm{~cm}^{-1}$ is assigned to the $\mathrm{C}-\mathrm{H}$ stretching vibration of PT. In addition, the absorption peak at $1250 \mathrm{~cm}^{-1}$ correspond to the stretching vibration of the $\mathrm{P}=\mathrm{N}$ of the cyclotriphosphazene skeleton in the HCCP structure. Importantly, the distinct absorption peak of $\mathrm{P}-\mathrm{O}-\mathrm{Ar}$ band was observed at $956 \mathrm{~cm}^{-1}$. PZPT microspheres were obtained by the polycondensation reaction between HCCP and FT, retaining the main structural features of HCCP and FT.

\subsection{Morphology of PZPT microspheres}

Fig. 2 shows the SEM images of PZPT microspheres, providing the microstructural information. The SEM image shows that the PZPT microsphere distinctly exhibit a regular and uniform spherical shape. Moreover, the surface of PZPT microspheres is smooth and clean, with an average diameter of approximately 1 
<smiles></smiles><smiles>ClP1(Cl)=NP(Cl)(Cl)=NP(Cl)(Cl)=N1</smiles>
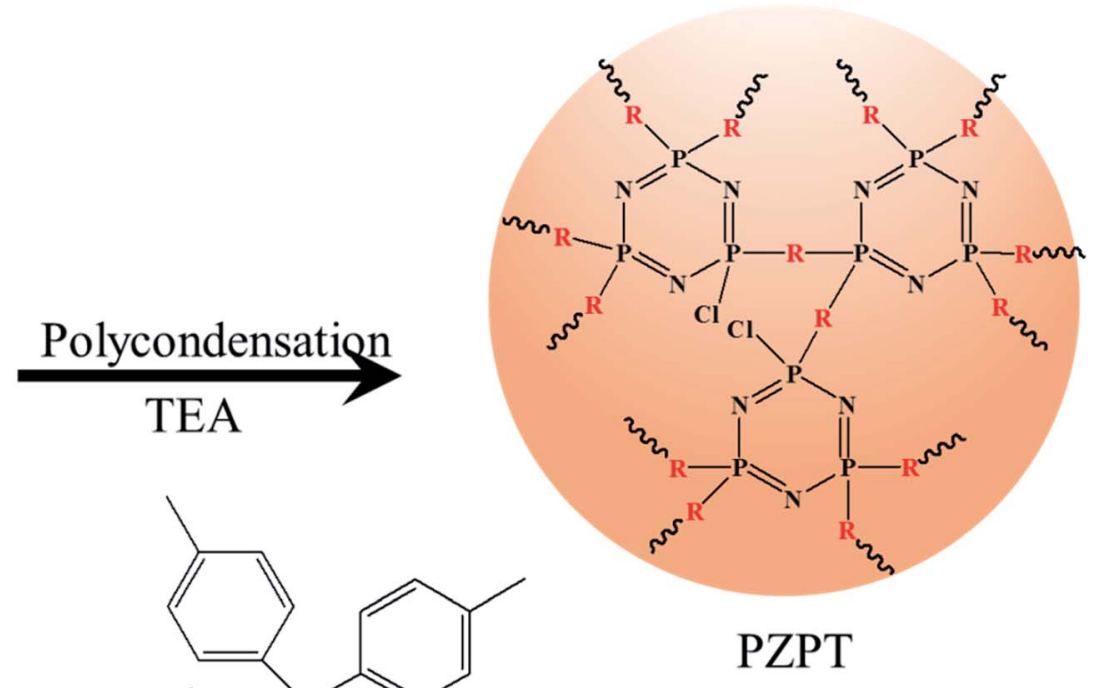

HCCP

$\mathrm{R}=$

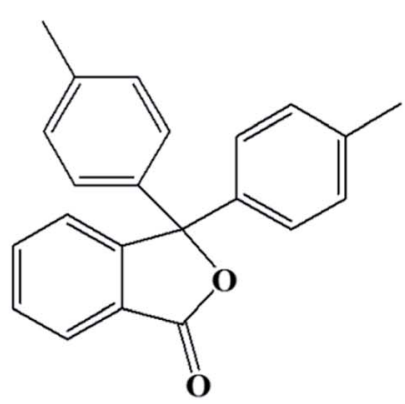

PZPT

Scheme 1 The synthesis route of PZPT microspheres.

$\mu \mathrm{m}$. The SEM results clearly demonstrate successful fabrication of PZPT microspheres.

\subsection{Curing behavior of $\mathrm{Ba}$ and Ba/PZPT systems}

3.3.1 Curing process. The non-isothermal DSC curves of $\mathrm{Ba}, \mathrm{Ba} / \mathrm{PZPT}-1 \%, \mathrm{Ba} / \mathrm{PZPT}-3 \%$, and $\mathrm{Ba} / \mathrm{PZPT}-5 \%$ at a heating rate of $5{ }^{\circ} \mathrm{C} \min ^{-1}$ are shown in Fig. 3. The curing characteristic parameters including the initial curing temperature $\left(T_{\mathrm{i}}\right)$, curing peak temperature $\left(T_{\mathrm{p}}\right)$, and final curing temperature $\left(T_{\mathrm{f}}\right)$ are listed in Table S1. $\uparrow$ Fig. 3 shows a single exothermic peak of the ring-opening thermal curing of the $\mathrm{Ba}$ and $\mathrm{Ba} / \mathrm{PZPT}$ curing systems. With increasing diameter of the PZPT microspheres, the $T_{\mathrm{i}}, T_{\mathrm{p}}$, and $T_{\mathrm{f}}$ decreased, whereas the curing temperature range $(\Delta T)$ increased. When the addition of 5\% PZPT microspheres, the $T_{\mathrm{i}}, T_{\mathrm{p}}$, and $T_{\mathrm{f}}$ decreased by 31,21 , and $6{ }^{\circ} \mathrm{C}$, respectively, compared to those of pure Ba. The $T_{\mathrm{i}}$ and $T_{\mathrm{p}}$ show slight obvious changes that may be ascribed to the catalytic properties of PZPT microspheres. The presence of phenols and phosphazenes form Lewis acids and organic acids can effectively shorten the induction time of benzoxazine curing and accelerate the reaction rate. ${ }^{5 \boldsymbol{b}}$ The processability of the material is related to the practical application of the material. Usually, the extrapolation method is used, i.e., $T_{\mathrm{i}}, T_{\mathrm{p}}$, and $T_{\mathrm{f}}$ is separately plotted against $\beta$ at different heating rates of $5,10,15$, and $20{ }^{\circ} \mathrm{C} \min ^{-1}$, and the static curing temperature when $\beta=0$ is obtained. The curing reaction parameters such as $T_{\mathrm{i}}, T_{\mathrm{p}}$, and $T_{\mathrm{f}}$ at different heating rates are shown Fig. S1† and Table 1. Finally, the curing process temperature is $200{ }^{\circ} \mathrm{C} / 2 \mathrm{~h}$, followed by $220^{\circ} \mathrm{C} / 2 \mathrm{~h}$.
3.3.2 Curing kinetics. To further discuss the curing behavior and curing kinetics of $\mathrm{Ba}$ and $\mathrm{Ba} / \mathrm{PZPT}$ mixture, the non-isothermal DSC curves of Ba, Ba/PZPT-1\%, Ba/PZPT-3\%, and $\mathrm{Ba} / \mathrm{PZPT}-5 \%$ at different heating rates of $5,10,15$ and $20{ }^{\circ} \mathrm{C} \min ^{-1}$ are presented Fig. 4. With increasing heating rate, the $T_{\mathrm{p}}$ moved to a higher temperature range. For example, when the heating rate was increased to $20{ }^{\circ} \mathrm{C} \mathrm{min}^{-1}$, the $T_{\mathrm{p}}$ of the $\mathrm{Ba}$, $\mathrm{Ba} / \mathrm{PZPT}-1 \%$, Ba/PZPT-3\%, and Ba/PZPT-5\% improved by 31, 29, 28 , and $28{ }^{\circ} \mathrm{C}$, respectively, compared to those at a heating rate of $5{ }^{\circ} \mathrm{C} \min ^{-1}$. Due to the thermal hysteresis effect, enough time is required for completing the curing reaction at a higher

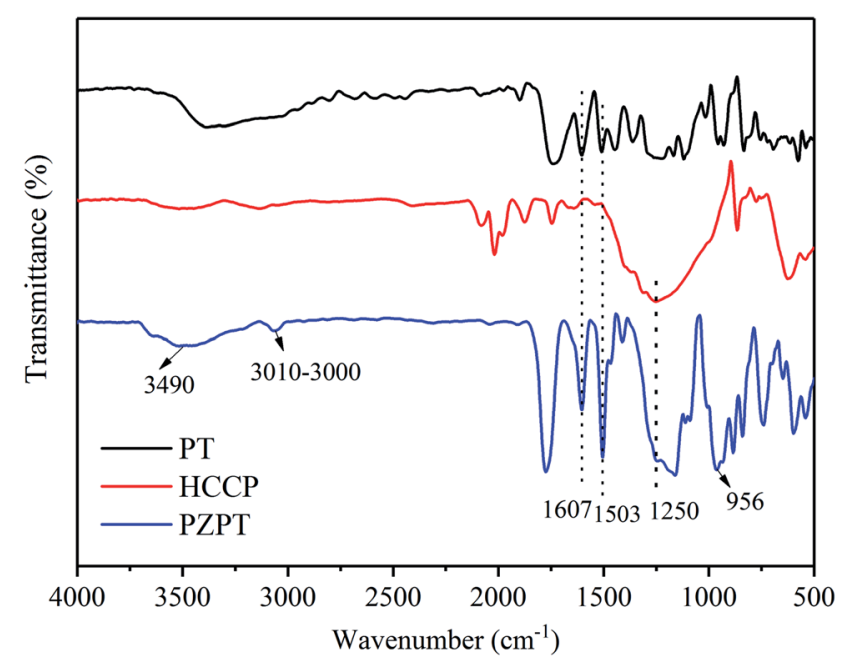

Fig. 1 FTIR spectra of HCCP, PT, and PZPT microspheres. 

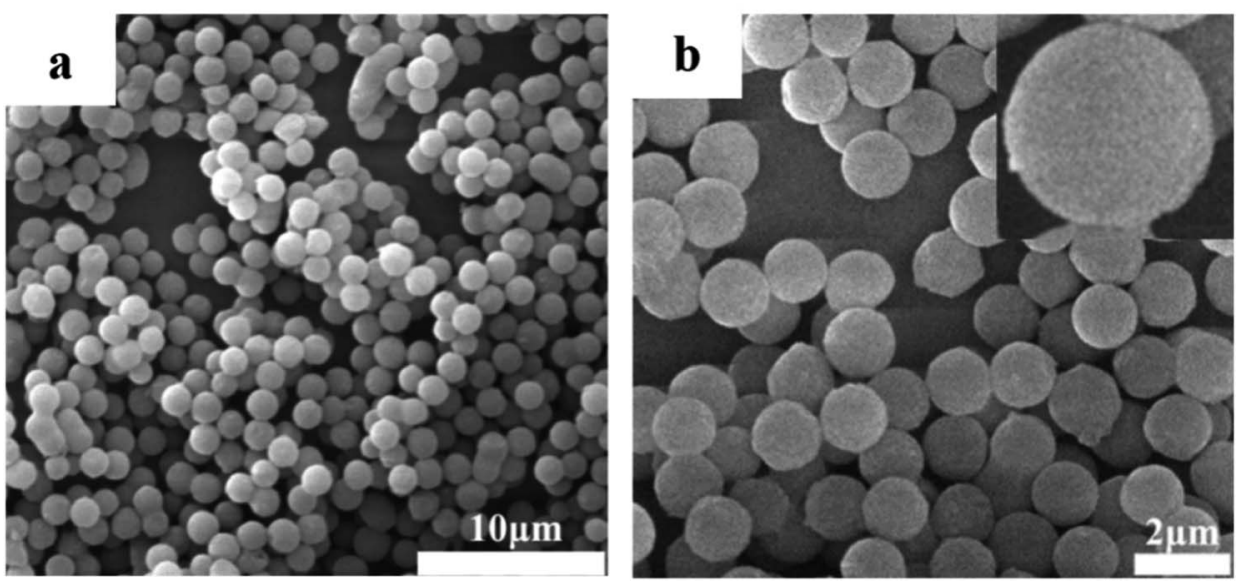

Fig. 2 SEM images of PZPT microspheres under different magnifications (a and b).

heating rate. Without assuming any model of kinetic parameters and integrating the exothermic peak, the Kissinger (eqn (1)) and Ozawa (eqn (2)) methods ${ }^{17}$ are often used for curing kinetics analysis to calculate the average activation energy of the exothermic reaction.

$$
\begin{gathered}
\ln \frac{\beta}{T_{\mathrm{p}}{ }^{2}}=-\frac{E_{\mathrm{a}}}{R T_{\mathrm{p}}}+\ln \left(\frac{A R}{E_{\mathrm{a}}}\right) \\
\ln \beta=\ln \left(\frac{A E_{\mathrm{a}}}{R}\right)-\ln F(\alpha)-1.052 \frac{E_{\mathrm{a}}}{R T_{\mathrm{p}}}-5.331
\end{gathered}
$$

where $\beta$ is the heating rate, $T_{\mathrm{p}}$ is the peak temperature, $A$ is the pre-exponential factor, $E_{\mathrm{a}}$ is the reaction activation energy, $\alpha$ is the conversion factor, $F(\alpha)$ is a constant function, and $R=8.314$ $\mathrm{J} \mathrm{mol}^{-1} \mathrm{~K}^{-1}$ is the universal gas constant.

Fig. S2 $\uparrow$ shows the plots of the plot of $\ln \left(\frac{\beta}{T_{\mathrm{p}}{ }^{2}}\right)$ against $\frac{1}{T_{\mathrm{p}}}$ for Ba and Ba/PZPT systems. The plot of $\ln \beta$ against $\frac{1}{T_{\mathrm{p}}}$ for $\mathrm{Ba}$ and $\mathrm{Ba} / \mathrm{PZPT}$ systems is shown in Fig. S3. $\dagger$ It is obvious that the

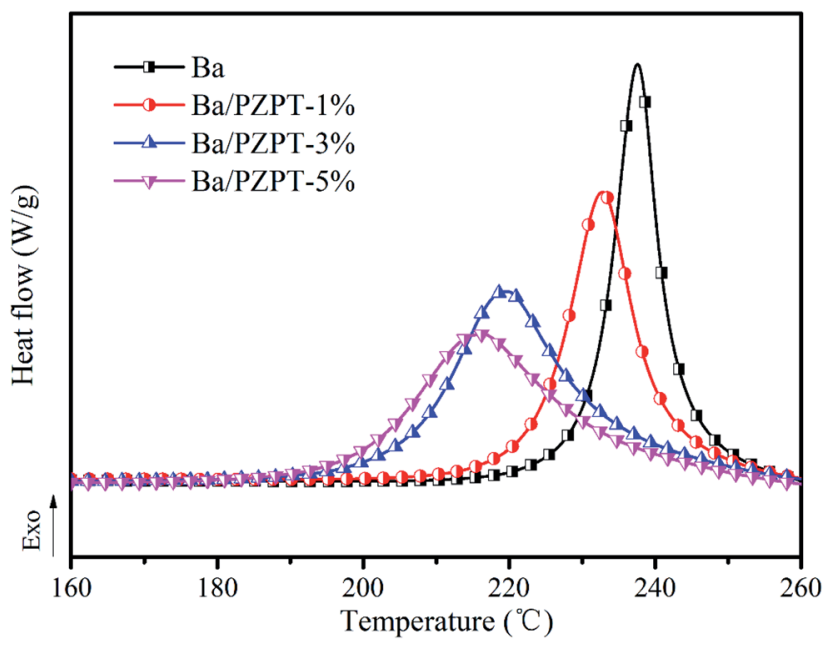

Fig. 3 DSC curves of the $\mathrm{Ba}$ and $\mathrm{Ba} / \mathrm{PZPT}$ systems at a heating rate of $5{ }^{\circ} \mathrm{C} \mathrm{min}^{-1}$. heating rates and the reciprocal of the peak temperature have a good linear relationship. According to the Kissinger and Ozawa method, the apparent activation energy and other kinetics parameters were calculated and are listed in Table 2. These results show that the average activation energies obtained from Kissinger are much higher than that of Ozawa methods, owing to different assumptions of the two methods. The Ozawa method considers that the degree of reaction conversion at the peak is constant, while the Kissinger method follows the assumption that the reaction rate is the highest at the peak temperature $\left(T_{\mathrm{p}}\right)$ of the reaction. Otherwise, with increasing number of PZPT microspheres, the average activation energy increases slightly. The $E_{\mathrm{a}}$ reflects the energy barriers that need to be overcome in the event of a chemical reaction. The highly crosslinked structure of PZPT microspheres limits the mobility of the Ba backbone and may attribute to a uniform cross-linking reaction between the PZPT microspheres and benzoxazine, requiring more energy to overcome higher energy barriers, thus increasing the activation energy of the curing reaction. ${ }^{18}$

Furthermore, the $E_{\mathrm{a}}$ values of Ba system can be easily obtained by Flynn-Wall-Ozawa method at the entire conversion rang. The slope should correspond to $E_{\mathrm{a}} / R$ at the particular conversion according to eqn (3) and (4).

$$
\begin{gathered}
\ln \beta=\ln \left(\frac{A E_{\mathrm{a}}}{R}\right)-\ln g(\alpha)-1.052 \frac{E_{\mathrm{a}}}{R T_{\mathrm{p}}}-5.331 \\
g(\alpha)=\int_{0}^{\alpha} \frac{\mathrm{d} \alpha}{f(\alpha)}
\end{gathered}
$$

Table 1 Curing characteristic parameters of $\mathrm{Ba}$ and Ba/PZPT systems at a heating rate of $0{ }^{\circ} \mathrm{C} \mathrm{min}^{-1}$

\begin{tabular}{llll}
\hline Samples & $T_{\text {i }}\left({ }^{\circ} \mathrm{C}\right)$ & $T_{\text {p0 }}\left({ }^{\circ} \mathrm{C}\right)$ & $T_{\text {f0 }}\left({ }^{\circ} \mathrm{C}\right)$ \\
\hline Ba & 224 & 229 & 235 \\
Ba/PZPT-1\% & 213 & 223 & 234 \\
Ba/PZPT-3\% & 198 & 213 & 229 \\
Ba/PZPT-5\% & 193 & 208 & 228
\end{tabular}



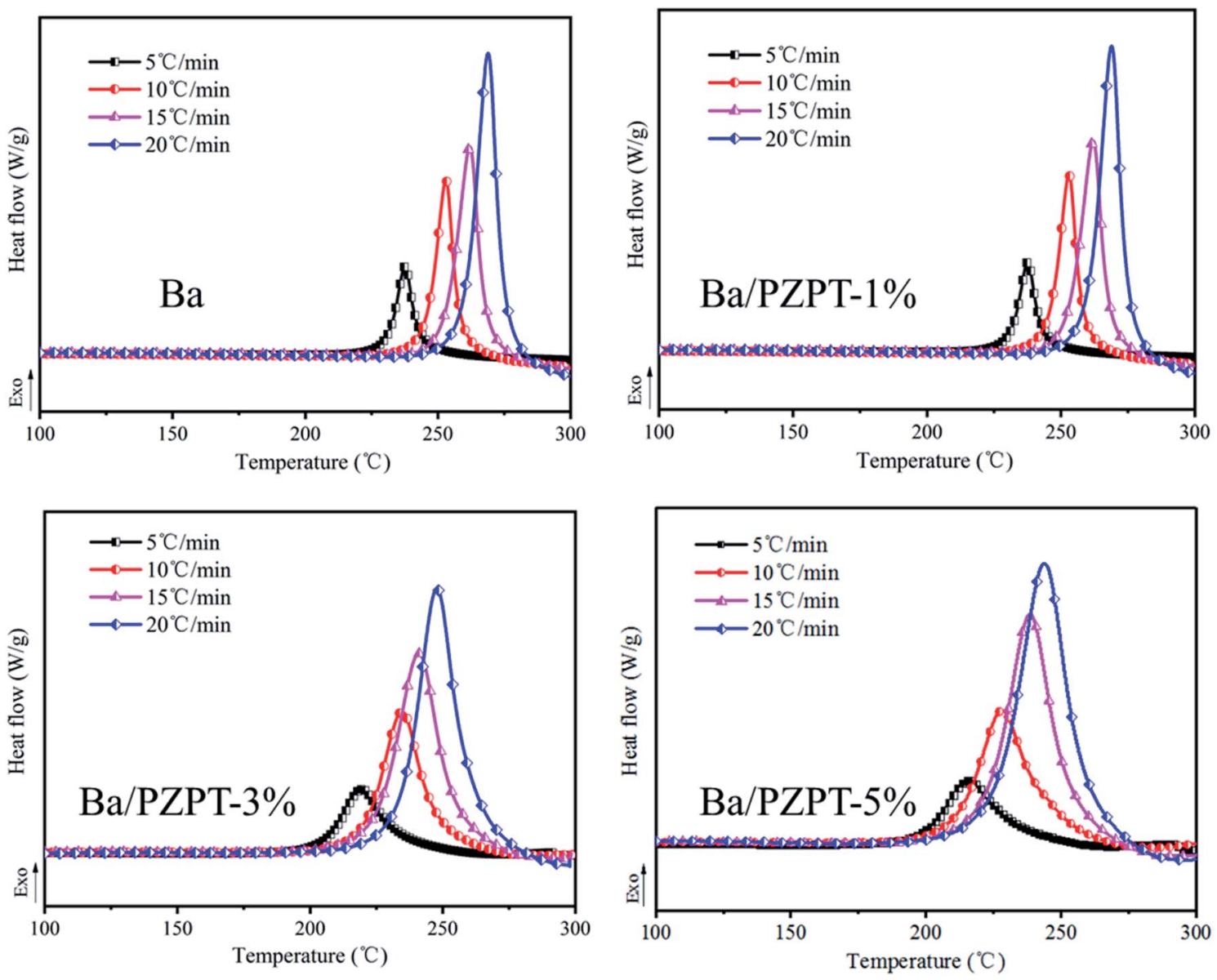

Fig. 4 Non-isothermal DSC curves of $\mathrm{Ba}$, Ba/PZPT-1\%, Ba/PZPT-3\%, and Ba/PZPT-5\%.

where $g(\alpha)$ is the integral conversion function, $T$ is the absolute temperature, and $f(\alpha)$ is the differential conversion function.

The $E_{\mathrm{a}}$ values of Ba and Ba/PZPT system are shown in Fig. 5, calculated for different reaction degree $(\alpha)$ ranging from 0.2 to 0.8 . Increasing $\alpha$ value, the $E_{\text {a }}$ gradually increased that indicates the polymerization process needs more energy to achieve. At the same time, the $E_{\mathrm{a}}$ values also increased with incorporating of PZPT. It is the reason that adding PZPT to Ba resin reduces the molecular mobility and decrease in active site.

Before establishing a kinetic model, judging the type of curing mechanism is necessary. In general, the curing mechanism of thermosetting resins is divided into two categories: an

Table $2 E_{\mathrm{a}}$ and pre-exponential factor of the $\mathrm{Ba}$ and Ba/PZPT system

\begin{tabular}{llrll}
\hline & \multicolumn{2}{c}{$E_{\mathrm{a}}\left(\mathrm{kJ} \mathrm{mol}^{-1}\right)$} & & \\
\cline { 2 - 3 } Samples & Kissinger & Ozawa & Average $E_{\mathrm{a}}\left(\mathrm{kJ} \mathrm{mol}^{-1}\right)$ & $\ln A$ \\
\hline Ba & 94.6 & 98.2 & 96.4 & 13.83 \\
Ba/PZPT-1\% & 96.2 & 101.3 & 98.8 & 14.64 \\
Ba/PZPT-3\% & 98.7 & 101.9 & 100.3 & 15.76 \\
Ba/PZPT-5\% & 99.6 & 102.0 & 100.8 & 15.95
\end{tabular}

$n^{\text {th }}$-order and an autocatalytic reaction model, which can be judged by the Friedman method (eqn (5) and (6)). ${ }^{19}$

$$
\ln \frac{\mathrm{d} \alpha}{\mathrm{d} t}=\ln \beta \frac{\mathrm{d} \alpha}{\mathrm{d} T}=\ln [A f(\alpha)]-\frac{E_{\mathrm{a}}}{R T}
$$

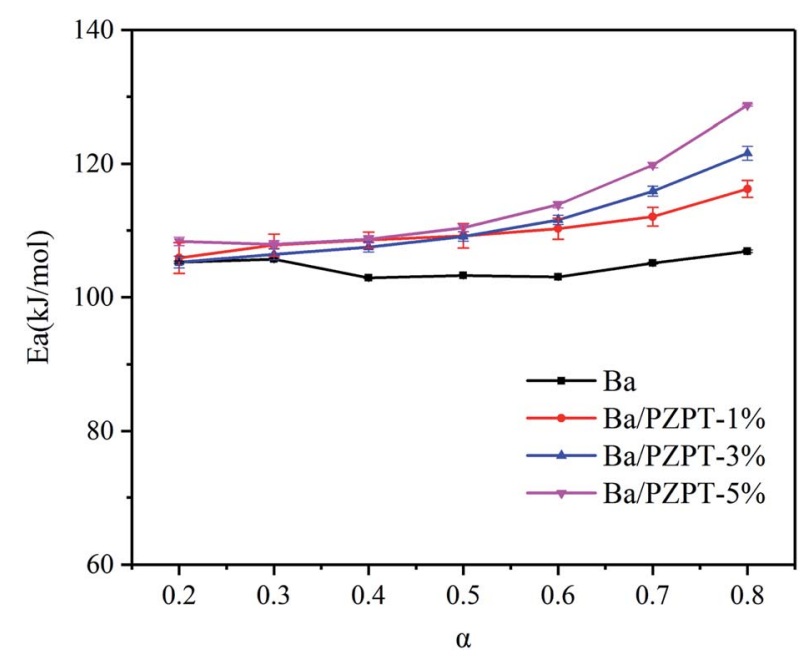

Fig. $5 E_{\mathrm{a}}$ values of $\mathrm{Ba}$ system obtained by Flynn-Wall-Ozawa method. 


$$
f(\alpha)=(1-\alpha)^{n}
$$

Eqn (5) is calculated by eqn (3) and (4) as:

$$
\ln [A f(\alpha)]=\ln \beta \frac{\mathrm{d} \alpha}{\mathrm{d} T}+\frac{E_{\mathrm{a}}}{R T}=\ln A+n \ln (1-\alpha)
$$

Fig. 6 shows the relationship between the plots of $\ln [A f(\alpha)]$ and $\ln (1-\alpha)$. The values of $\ln [A f(\alpha)]$ can be calculated by eqn (5) using the average activation energy from the Kissinger and Ozawa method. According to Jubsilp et al.,${ }^{20}$ for $n^{\text {th }}$ order curing mechanism, the relationship between the $\ln [A f(\alpha)]$ against $\ln (1$ $-\alpha$ ) should yield a straight line with a slope. However, the plot would show a maximum of $\ln (1-\alpha)$ approximately 0.51 to 0.22 , equivalent to an $\alpha$ approximately in the range $0.2-0.4$, indicating an autocatalytic process. In other words, the curing mechanism of $\mathrm{Ba}$ and $\mathrm{Ba} / \mathrm{PZPT}$ systems follows an autocatalytic reaction model. Generally, the autocatalytic nature of Ba curing kinetics is that phenolic groups generated from the benzoxazine ring opening can actually further accelerate the ring opening process. ${ }^{19 a}$ Fig. 6 shows that the Friedman curves are in good agreement with the literature data, showing the maximum reaction rate at $20-40 \%$ conversion. ${ }^{21}$

\subsection{Curing behavior of Ba and Ba/PZPT systems}

The polymerization behaviors of $\mathrm{Ba}$ and $\mathrm{Ba} / \mathrm{PZPT}$ oligomers were also confirmed by in situ FTIR analyses in order to further investigate the changes in the internal chemical bonds of oligomers. Fig. 7 and 8 show the FTIR spectra of pure $\mathrm{Ba}$ and $\mathrm{Ba} /$ PZPT-3\% at a heating rate of $5{ }^{\circ} \mathrm{C} \min ^{-1}$, respectively, in the temperature range from $160{ }^{\circ} \mathrm{C}$ to $250{ }^{\circ} \mathrm{C}$ at different temperatures. Fig. 7 shows the characteristic bands at $945 \mathrm{~cm}^{-1}$, attributed to the stretching vibration of the oxazine ring, and the intensity of these bands gradually decreases at temperatures

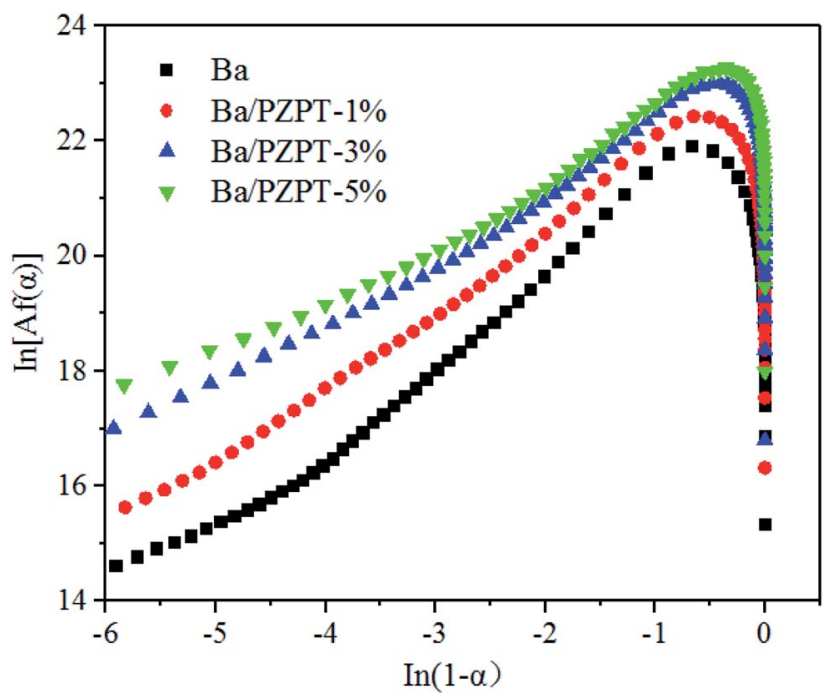

Fig. 6 Plots of $\ln [A(\alpha)]$ and $\ln (1-\alpha)$ of the $B a$ and $B a / P Z P T$ systems at a heating rate of $5{ }^{\circ} \mathrm{C} \mathrm{min}^{-1}$ by the average activation energy from Flynn-Wall-Ozawa method.

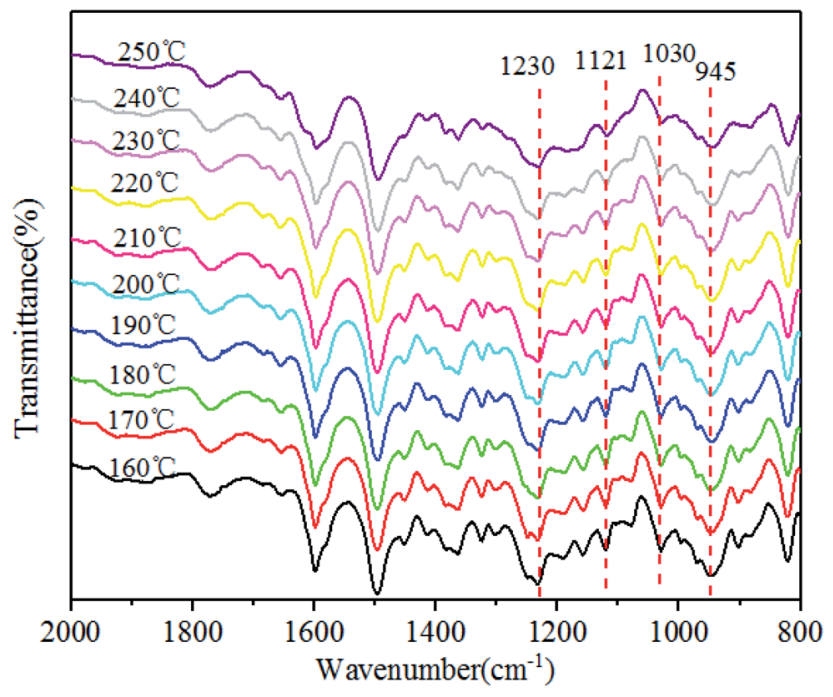

Fig. 7 In situ FTIR spectra of pure Ba at different temperatures.

more than $230{ }^{\circ} \mathrm{C}$. Besides, the same phenomenon was observed for the band at 1230 and $1030 \mathrm{~cm}^{-1}$, attributed to the asymmetric and symmetric stretching vibration of the $\mathrm{C}-\mathrm{O}-\mathrm{C}$ bonds in the oxazine group, respectively, clearly indicating the ring-opening polymerization of the oxazine ring. ${ }^{22}$ However, the intensity of the peak at approximately $1121 \mathrm{~cm}^{-1}$ attributed to the Ar-C-Ar stretching vibration increased slightly at $>230{ }^{\circ} \mathrm{C}$, suggesting the formation of more cross-linked structures during the curing process of $\mathrm{Ba}^{18}$

With the addition of PZPT microspheres, the change in the main functional group of Ba shifts to low temperature as shown in Fig. 8. The intensity of the related absorption speaks at 945 , 1030 , and $1230 \mathrm{~cm}^{-1}$ begins to decrease at $210^{\circ} \mathrm{C}$, and the peaks disappeared at $250{ }^{\circ} \mathrm{C}$. This phenomenon is consistent with the aforementioned DSC test results. Thus, the hydroxyl and Lewis

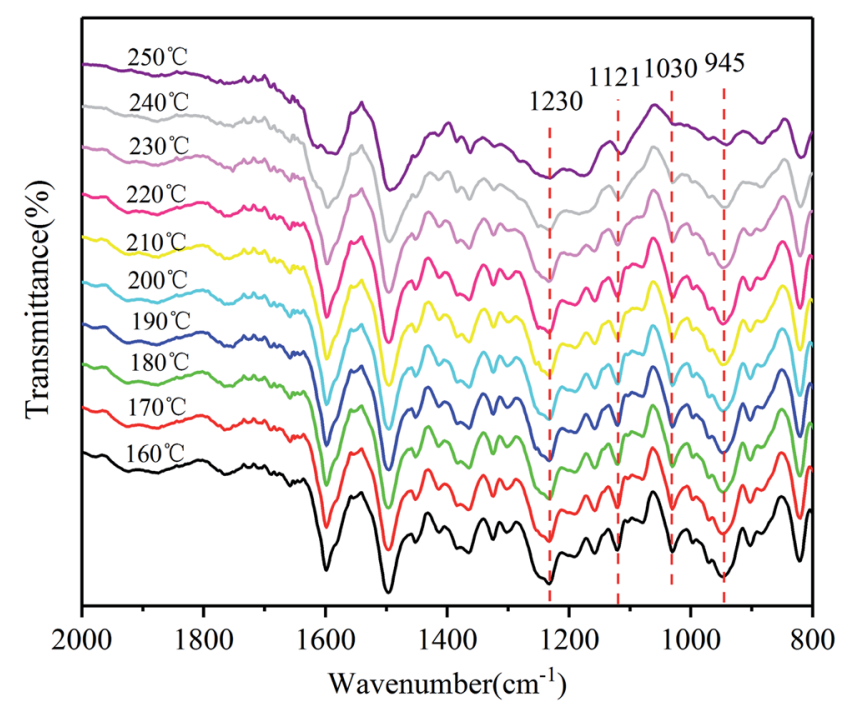

Fig. 8 In situ FTIR spectra of Ba/PZPT-3\% composites at different temperatures. 

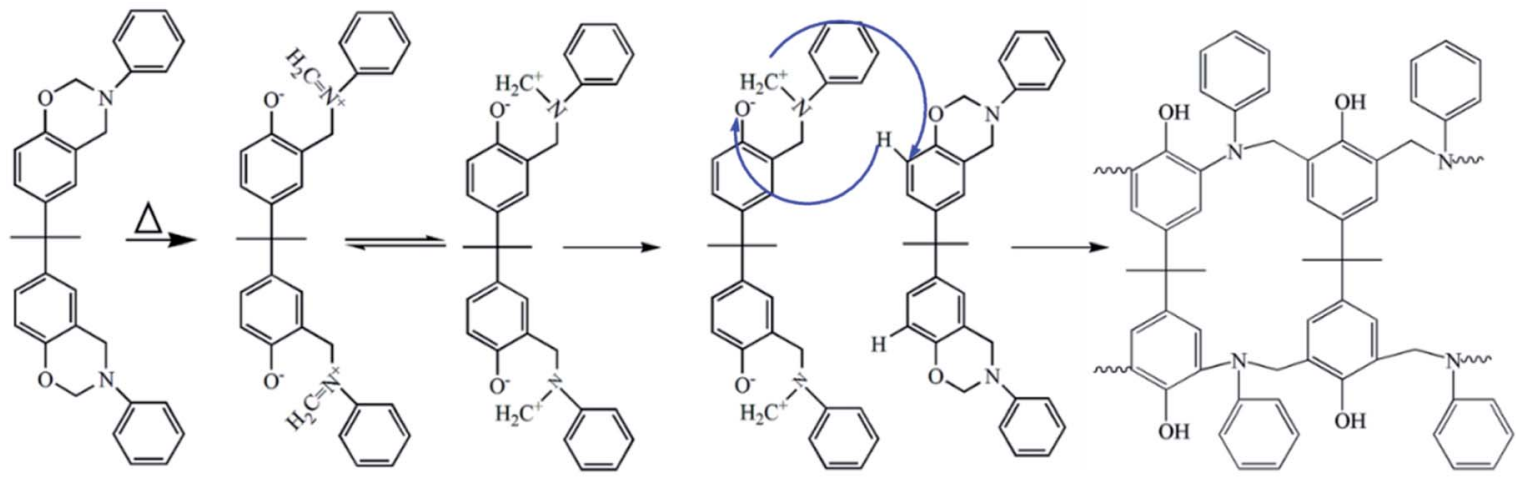

Scheme 2 The thermally catalyzed reaction mechanism of the benzoxazine curing process.

acid of PZPT catalyzes the ring-opening polymerization of Ba monomers, thus decreasing the curing temperature. Based on the previous reports, the Lewis acid providing protons by microspheres can initiate the acid catalyzed ring-opening polymerization of benzoxazine, generating the cross-linked network of polybenzoxazine by further reaction with Ba monomers. Moreover, at $210{ }^{\circ} \mathrm{C}$, the intensity of the characteristic absorption band of Ar-C-Ar at $1121 \mathrm{~cm}^{-1}$ gradually increases due to the formation of the cross-linking groups at higher temperatures. Otherwise, this reaction can increase the molecular weight of the polymer, illustrating the better thermal property of $\mathrm{Ba} / \mathrm{PZPT}$ system. Scheme 3 shows the reaction mechanism of the Ba/PZPT system curing process.

Schemes 2 and 3 show the reaction mechanism of the Ba and $\mathrm{Ba} / \mathrm{PZPT}$ system curing process, respectively. The specific pathway for the thermal ring opening of pure benzoxazine is presumed to undergo the following steps: first, the $\mathrm{O}-\mathrm{C}$ bond in the $\mathrm{Ar}-\mathrm{O}-\mathrm{CH}_{2}$ structure in the oxazine ring of benzoxazine is cleaved at high temperature to form a carbocation active center $\left(\mathrm{C}^{+}\right)$and oxygen anion $\left(\mathrm{O}^{-}\right)$. Next, the $\mathrm{O}^{-}$takes away the larger electrophilic ortho-position $\mathrm{H}$ on the other oxazine ring to form a phenolic hydroxyl group, and the $\mathrm{N}^{-} \mathrm{CH}$ combines at the ortho-position of the ring in another oxazine ring to form a Mannich bridge. At the same time, another cationic active center is generated, and the polymer chain continuously grows until a three-dimensional network structure is formed. However, the curing of benzoxazine is characterized by the acidcatalyzed curing behavior after the addition of microspheres. At a certain heating rate, when the temperature reaches the catalytic curing temperature, first the benzoxazine monomer undergoes ring opening under phosphate catalysis, and the resulting phenolic hydroxyl group further catalyzes the curing reaction of benzoxazine.

\subsection{Thermal stability}

Taking into account the effect of curing temperature, 3 and 5 wt $\%$ of PZPT microspheres were selected for further study for the performance analysis. The thermal properties of PZPT, PBa and PBa/PZPT composites were tested by TGA, and the TG and DTG curves are shown in Fig. 9. Table 3 shows the temperature at $5 \mathrm{wt} \%$ mass loss, the temperature at the maximum mass loss rate of materials, and the weight percentage of residue at $800{ }^{\circ} \mathrm{C}$, defined by the onset degradation temperature $\left(T_{\text {onset }}\right)$, the maximum degradation temperature $\left(T_{\max }\right)$, and the weight residue rate $\left(Y_{\mathrm{c}}\right)$, respectively. Noticeably, with increasing of the temperature, PZPT microspheres exhibits a lower weight loss at temperatures up to $800{ }^{\circ} \mathrm{C}$, indicating that the PZPT microspheres have high thermal stability. The pure PBa displays only one-phase weight loss in the nitrogen atmosphere with the $T_{\text {onset }}$ of approximately $337.6{ }^{\circ} \mathrm{C}$, followed by the $Y_{\mathrm{c}}$ of $31.8 \%$, as
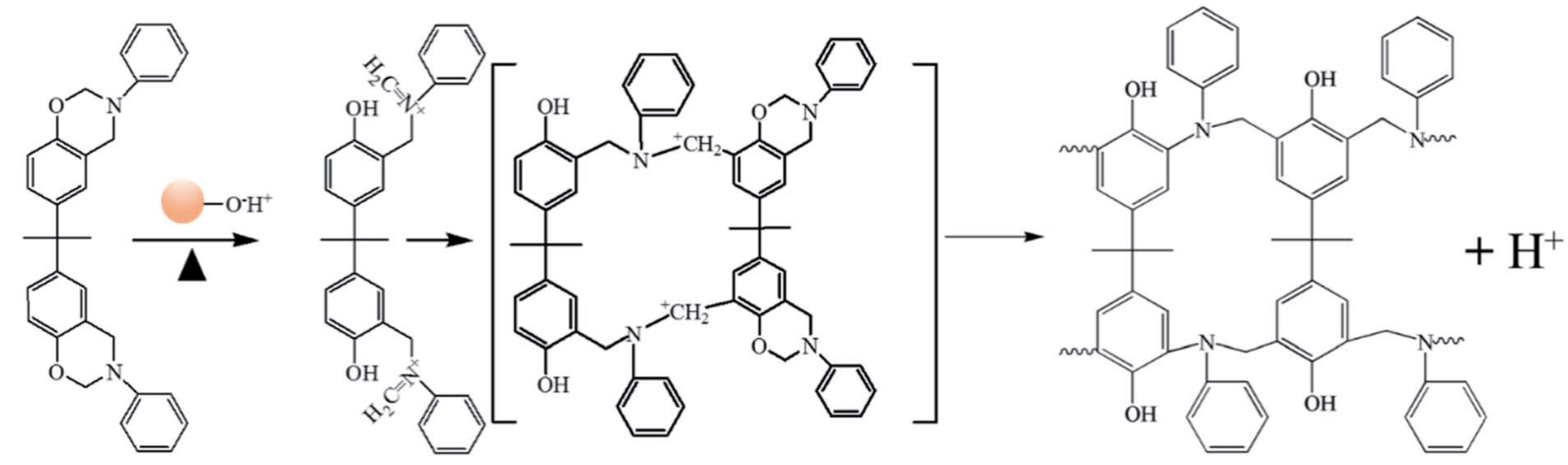

Scheme 3 The acid catalyzed reaction mechanism of the benzoxazine curing process. 

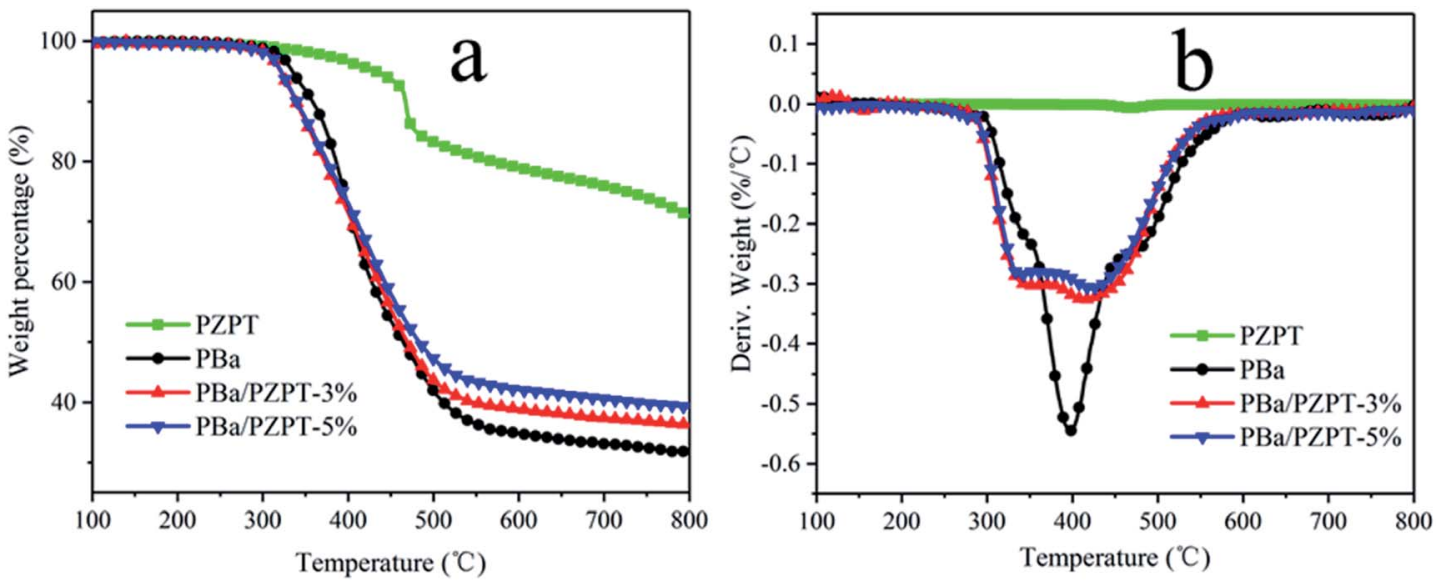

Fig. 9 TGA (a) and DTG (b) curves of PZPT, pure PBa and its composites in a nitrogen atmosphere.

shown by Fig. 9(a). After the incorporation of 5 wt $\%$ PBa/PZPT, the $T_{\text {onset }}$ of the composites slightly reduced compared to that of the pure $\mathrm{PBa}$, and the $Y_{\mathrm{c}}$ increased to approximately $39.3 \%$, showing a slightly better thermal stability. This observation is likely to be attributed to the fact that a protective barrier provided by PZPT microspheres forming cross linking network can prohibit the mass and heat transfer between the air and internal matrix to an extreme extent. However, the composites demonstrate two-phase weight loss at 334.8 and $426.3{ }^{\circ} \mathrm{C}$ as shown in Fig. 9(b), owing to the fact that the Lewis acids and organic acids generated by microspheres can effectively catalyze the dissociation of the weak bond $\left(-\mathrm{CH}_{2}-\mathrm{N}(-\mathrm{R})-\right)$ in the PBa matrix, according to the degradation in the first stage. The weight loss at the higher temperature stage is attributed to the further decomposition of PZPT.

\subsection{Flame retardancy of $\mathrm{PBa} / \mathrm{PZPT}$ composites}

PZPT microspheres is considered to have flame retardant properties attributing to the presence of phosphorus and nitrogen elements. Thus, the incorporation of microspheres into PBa resin is an effective technique for improving its fire retardant properties, and this can be confirmed by the cone calorimeter analysis. The heat release rate (HRR), total heat release (THR), carbon monoxide production (COP), and total smoke release (TSR) versus time curves of PBa and PBa/PZPT composites are shown in Fig. 10. The heat release rate (PHRR) peak value for pure PBa is $593 \mathrm{~kW} \mathrm{~m}^{-2}$ as shown in Fig. 10(a). Increasing to $5 \mathrm{wt} \%$ PZPT, the PHRR obviously deceased by $57.8 \%$. In addition, the THR value of $5 \mathrm{wt} \% \mathrm{PBa} / \mathrm{PZPT}$ decreased to $17.3 \%$ compared to that of the pristine PBa. The decrease in the PHRR and HRR indicates the good flame retardancy among the rest of the PBa composites. This phenomenon may be related to the physical barrier effect of PZPT microspheres that is the carbonization behavior, which inhibits the heat and mass transfer between gas and material interior. Fig. 10(c) shows that due to multi-aromatic structure, pure PBa present a higher COP and TSR values. The COP and TSR value slightly decreased with the addition of microspheres from $0.015 \mathrm{~g} \mathrm{~s}^{-1}$ for pure PBa to
$0.007 \mathrm{~g} \mathrm{~s}^{-1}$ for PBa/PZPT-5\% with a decrease of $53.3 \%$, indicating good resistance from the toxic gases and smog production after adding microspheres. ${ }^{12 a}$

The digital images of the cone calorimeter test of the char residues of $\mathrm{PBa}$ and $\mathrm{PBa} / \mathrm{PZPT}-5 \%$ was shown in Fig. 11. The height of the residual carbon of $\mathrm{PBa} / \mathrm{PZPT}-5 \%$ is more than that of pure PBa. Fig. 11(c and d) shows that a compact and continuous char layer is formed after the combustion of PBa/ PZPT-5\%, dehydrating the charcoal while expanding to liberate the gas upon exposure to heat or flame. Under the action of gas, a carbon layer structure enclosed by a fluffy hair hole is formed. The carbon layer is non-combustible and acts as a barrier to heat, air, and hydrolysis products. When the amount of oxygen and heat in the environment is not enough, the combustion of the polymer is difficult to proceed, leading to selfextinguishment.

\subsection{Dynamic mechanical properties}

The $\tan \delta$ and storage modulus of pure PBa and PBa/PZPT composites were tested by DMA analysis, as shown in Fig. 12 and 13 , respectively. The peak of $\tan \delta$ slightly shifts to the lower temperature, as shown in Fig. 12. With increasing loading to $5 \mathrm{wt} \%$ PZPT microspheres, the transition temperature $\left(T_{\mathrm{g}}\right)$ decreases to approximately $5{ }^{\circ} \mathrm{C}$. The decrease in $T_{\mathrm{g}}$ is ascribed to the fact that PBa composites hinder the efficiency of ringopening crosslinking of the curing process of the Ba monomers, thus decreasing the PBa crosslink density. ${ }^{2 b}$

Fig. 13 shows the storage modulus of $\mathrm{PBa} / \mathrm{PZPT}-3 \%$ and pure $\mathrm{PBa}$, and both the curves are basically the same with no

Table 3 Thermogravimetric analysis results of PBa and PBa/PZPT-5\%

\begin{tabular}{lllll}
\hline Samples & $T_{\text {onset }}\left({ }^{\circ} \mathrm{C}\right)$ & $T_{\max }\left({ }^{\circ} \mathrm{C}\right)$ & & $Y_{\mathrm{c}}(\%)$ \\
\hline $\mathrm{PBa}$ & 337.6 & 397.0 & & 31.8 \\
$\mathrm{PBa} / \mathrm{PZPT}-3 \%$ & 321.8 & 337.8 & 418.7 & 37.4 \\
PBa/PZPT-5\% & 321.0 & 334.8 & 436.3 & 39.3
\end{tabular}



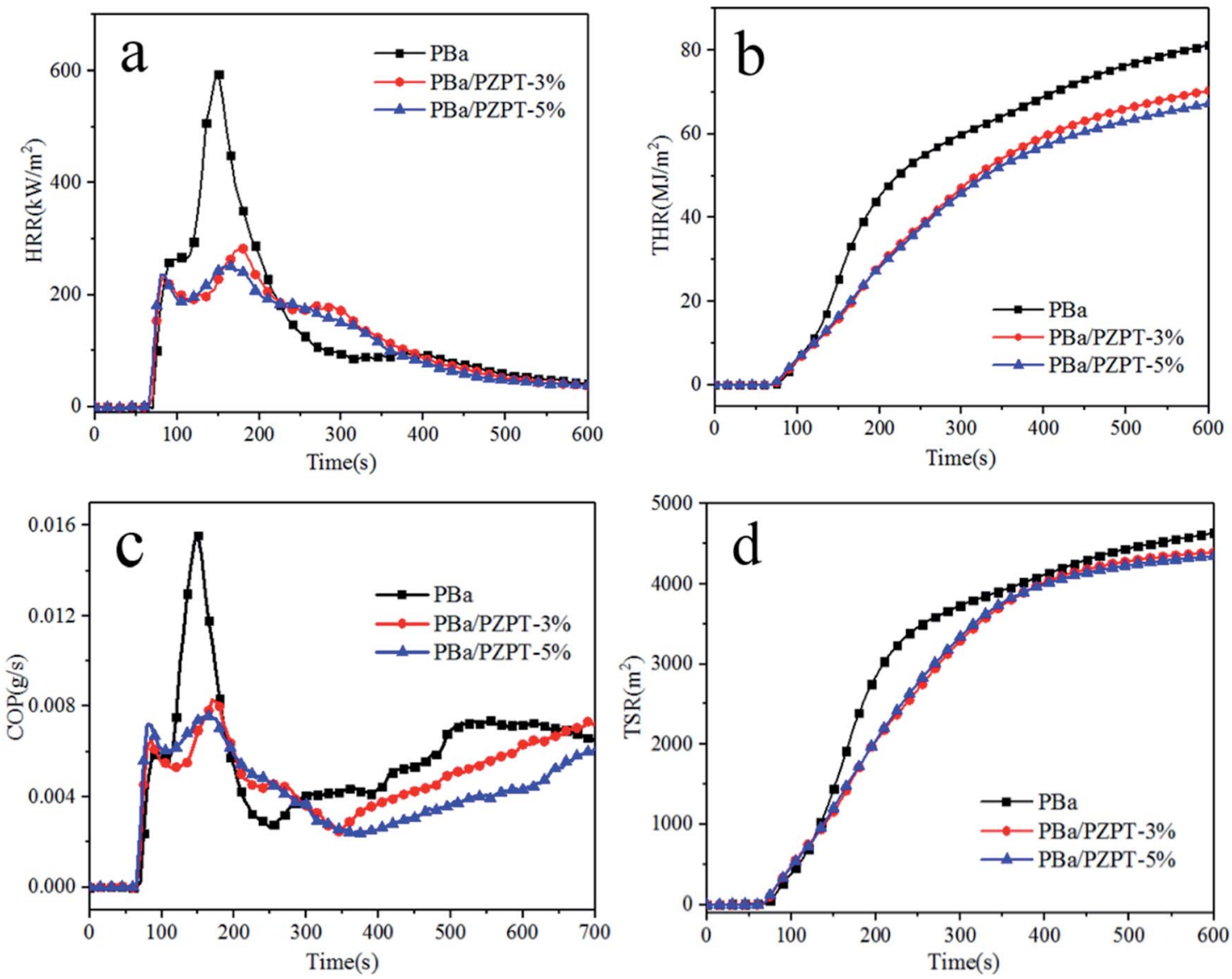

Fig. 10 HRR (a), THR (b), COP (c), and TSR (d) versus time curves of PBa and PBa/PZPT composites obtained from the cone calorimetry test.

significant change. In the presence of $5 \mathrm{wt} \%$ PZPT, the $E$ value increases significantly. However, the $E$ value is lower than that of PBa until temperature rises to approximately $200^{\circ} \mathrm{C}$, and this is attributed to the fact that the addition of highly crosslinked rigid microspheres increases the rigidity of the polymer system,
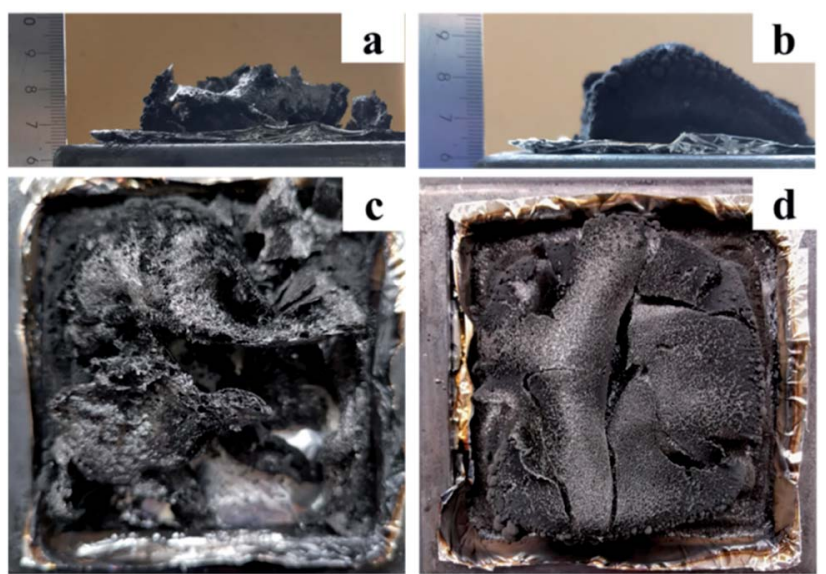

.

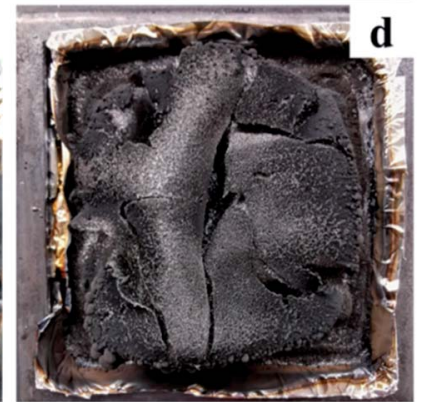

Fig. 11 Digital photos of the char residues of PBa ( $a$ and $b$ ) and PBa/ PZPT-5\% (c and d) after the cone calorimeter test. exhibiting a high modulus of storage. When the temperature rises, the storage modulus of the system was decreased due to high-temperature-induced softening of the polymer chains, indicating the transformation from the glassy to the rubbery state.

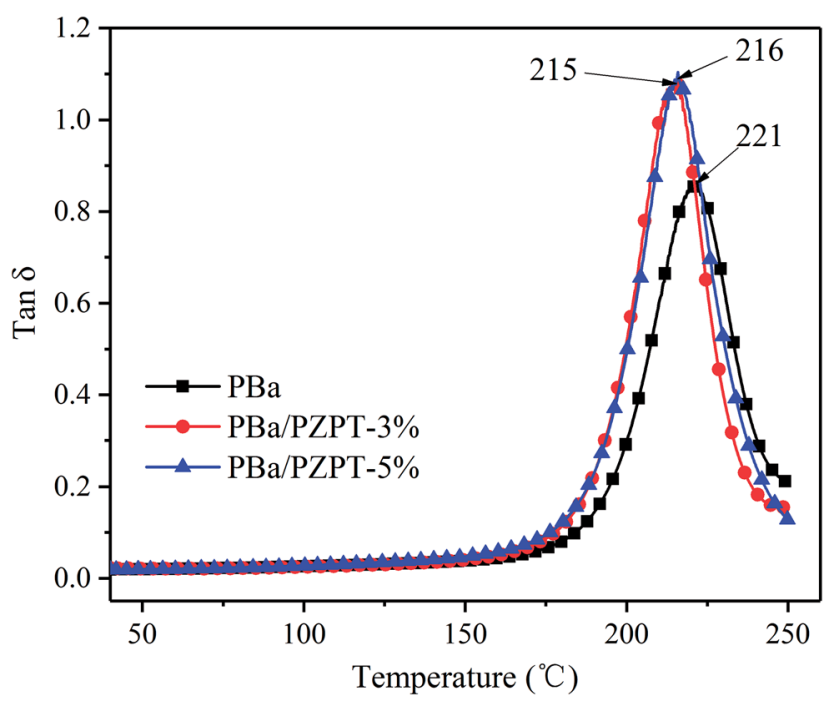

Fig. $12 \tan \delta$ of the pure PBa, PBa/PZPT-3\%, and PBa/PZPT-5\%. 


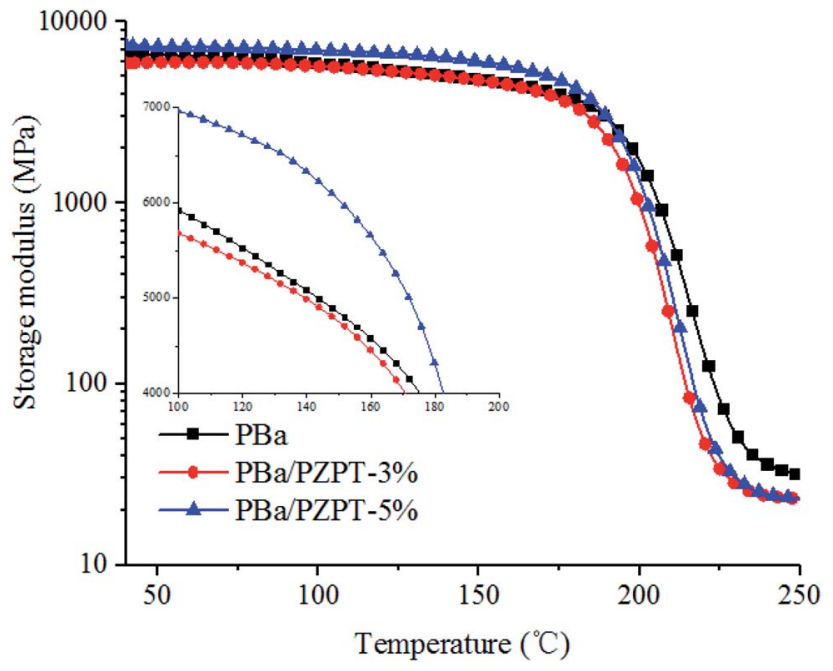

Fig. 13 Storage modulus of the pure PBa, PBa/PZPT-3\% and PBa/ PZPT-5\%.

\section{Conclusions}

In conclusion, PZPT microspheres were successfully synthesized via the ultrasonic assisted condensation polymerization, followed by the melt bending incorporating the benzoxazine resin. The effects of PZPT microspheres on the curing kinetics and behaviors of Ba were systematically analyzed by DSC and in situ FTIR analyses. The $T_{\mathrm{i}}, T_{\mathrm{p}}$, and $T_{\mathrm{f}}$ of $\mathrm{Ba} / \mathrm{PZPT}-5 \%$ reduced to 31,21 , and $6{ }^{\circ} \mathrm{C}$, respectively, compared to those of the pure $\mathrm{Ba}$, as evidenced by the non-isothermal DSC results. $\mathrm{Ba}$ and $\mathrm{Ba} /$ PZPT are the autocatalytic curing models based on the Friedman calculation method; however, the catalytic ring opening mechanisms of $\mathrm{Ba}$ and $\mathrm{Ba} / \mathrm{PZPT}$ systems are obviously different as $\mathrm{Ba}$ is thermally catalyzed whereas $\mathrm{Ba} / \mathrm{PZPT}$ systems is acid catalyzed. The TGA, CONE, and DMA analyses revealed the thermal stability, flame retardancy, and thermomechanical properties of the $\mathrm{PBa}$ and $\mathrm{PBa} / \mathrm{PZPT}$ composites. The TGA results demonstrated that the $\mathrm{PBa}$ residue at $800{ }^{\circ} \mathrm{C}$ increased with the incorporation of PZPT, indicating a better char formation process. The PHRR and THR values of PBa/PZPT-5\% composites obviously deceased by $57.8 \%$ and $17.3 \%$ compared to those of the pristine PBa. Moreover, the smoke released from the PZPT/PBa system significantly reduced with the loading of microspheres. The DMA results demonstrated the $T_{\mathrm{g}}$ of PBa flame retardant composites around $210{ }^{\circ} \mathrm{C}$, suggesting many potential applications of the synthesized $\mathrm{PBa}$ composites.

\section{Conflicts of interest}

There are no conflicts to declare.

\section{Acknowledgements}

This work was supported by the Science and Technology Plan Project in Sichuan Province (2019YFG0242), the National Natural Science Foundation of China (51703191), and the Open
Experiment of Southwest Petroleum University (KSZ18515), respectively.

\section{References}

1 (a) T. Takeichi, T. Kawauchi and T. Agag, Polym. J., 2008, 40, 1121-1131; (b) X. Xiong, Z. Zhang, R. Ren, X. Cui and P. Chen, Polym. Test., 2018, 72, 232-237; (c) H. Wang, J. Wang, X. He, T. Feng, N. Ramdani, M. Luan, W. Liu and X. Xu, RSC Adv., 2014, 4, 64798-64801.

2 (a) C. Liu, D. Shen, R. M. a. Sebastián, J. Marquet and R. Schönfeld, Macromolecules, 2011, 44, 4616-4622; (b) C. Andronescu, S. A. Garea, E. Vasile and H. Iovu, Compos. Sci. Technol., 2014, 95, 29-37; (c) H. Kimura, A. Matsumoto and K. Ohtsuka, J. Appl. Polym. Sci., 2010, 109, 1248-1256; (d) S. Li, C. Zhao, Y. Wang, H. Li and Y. Li, J. Mater. Sci., 2018, 53, 7344-7356.

3 (a) H. Liu, X. Wang and D. Wu, Thermochim. Acta, 2015, 607, 60-73; (b) H. Yan, C. Sun, Z. Fang, X. Liu, J. Zhu and H. Wang, Polymer, 2016, 97, 418-427; (c) S. Zhang, X. Li, H. Fan, Q. Fu and Y. Gu, Mater. Chem. Phys., 2019, 223, 260-267.

4 (a) S. Zhang, P. Yang, Y. Bai, T. Zhou, R. Zhu and Y. Gu, ACS Omega, 2017, 2, 1529-1534; (b) X. Wang, L. Zong, J. Han, J. Wang, C. Liu and X. Jian, Polymer, 2017, 121, 217-227; (c) Y.-T. Liao, Y.-C. Lin and S.-W. Kuo, Macromolecules, 2017, 50, 5739-5747; (d) K. Zhang, J. Qiu, S. Li, Z. Shang and J. Wang, J. Appl. Polym. Sci., 2017, 134, 45408; (e) X. Wang, N. Li, J. Wang, G. Li, L. Zong, C. Liu and X. Jian, Compos. Sci. Technol., 2018, 155, 11-21; (f) C. H. Lin, Z. J. Chen, C. H. Chen, M. W. Wang and T. Y. Juang, ACS Omega, 2017, 2, 3432-3440; (g) X. Wang, J. Wang, C. Liu and X. Jian, Polym. Int., 2018, 67, 100-110.

5 (a) C. Zhao, P. Li, D. He, Y. Li, F. Lei and H.-J. Sue, RSC Adv., 2016, 6, 73485-73495; (b) M. Zeng, J. Wang, R. Li, J. Liu, W. Chen, Q. Xu and Y. Gu, Polymer, 2013, 54, 3107-3116.

6 (a) R. Lin, Y. Zhu, Y. Zhang, L. Wang and S. Yu, Eur. Polym. J., 2018, 102, 141-150; (b) L. Han, K. Zhang, H. Ishida and P. Froimowicz, Macromol. Chem. Phys., 2017, 218, 1600562.

7 (a) M. Taylor, G. Cavalli and I. Hamerton, Macromol. Chem. Phys., 2019, 220, 1800282; (b) R. Andreu, J. A. Reina and J. C. Ronda, J. Polym. Sci., Part A: Polym. Chem., 2008, 46, 3353-3366.

8 I. Hamerton, L. McNamara, B. Howlin, P. Smith, P. Cross and S. Ward, Macromolecules, 2014, 47, 1935-1945.

9 M. J. Fan, Y. Zhou, Y. H. Luan, Q. Zang, D. X. Zhang, C. Y. Shang and W. G. Jiang, Solid State Phenom., 2017, 266, 128-134.

10 P. Yang and Y. Gu, J. Polym. Res., 2011, 18, 1725-1733.

11 L. Zhao, L. Yuan, G. Liang and A. Gu, RSC Adv., 2015, 5, 58989-59002.

12 (a) S. Qiu, X. Wang, B. Yu, X. Feng, X. Mu, R. K. K. Yuen and Y. Hu, J. Hazard. Mater., 2017, 325, 327-339; (b) C. Liu, J. Huang, J. Zhu, C. Yuan, B. Zeng, G. Chen, Y. Xu and L. Dai, J. Appl. Polym. Sci., 2018, 135, 45721. 
13 (a) H. Liu, X. Wang and D. Wu, Polym. Degrad. Stab., 2015, 118, 45-58; (b) J. Jing, Y. Zhang, X. Tang, Y. Zhou, X. Li, B. K. Kandola and Z. Fang, Polymer, 2017, 108, 361-371.

14 K. Chen, X. Huang, X. Tang and L. Zhu, J. Macromol. Sci., Part B: Phys., 2011, 51, 269-274.

15 (a) T. N. Thompson, S. Ramos-Hunter, J. Robertson and N. Y. Arnett, Tetrahedron Lett., 2013, 54, 5311-5313; (b) C. Zhao, L. Zhao, X. He, H. Gou and Y. Li, Acta Polym. Sin., 2018, 10, 1336-1344.

16 (a) X. Zhou, S. Qiu, W. Xing, C. Gangireddy, Z. Gui and Y. Hu, ACS Appl. Mater. Interfaces, 2017, 9, 29147-29156; (b) S. Xiao, M. Chen, L. Dong, C. Deng, L. Chen and Y. Wang, Chin. J. Polym. Sci., 2013, 32, 98-107.
17 (a) K. Zeng, J. Huang, J. Ren and Q. Ran, Macromol. Chem. Phys., 2019, 220, 1800340; (b) R. Ambrožič, U. Šebenik and M. Krajnc, Polymer, 2015, 76, 203-212.

18 J. Zhou, C. Zhao, L. Liu, J. Ding and Y. Li, Thermochim. Acta, 2018, 661, 106-115.

19 (a) Y. Bai, P. Yang, S. Zhang, Y. Li and Y. Gu, J. Therm. Anal. Calorim., 2015, 120, 1755-1764; (b) C. Jubsilp, S. Damrongsakkul, T. Takeichi and S. Rimdusit, Thermochim. Acta, 2006, 447, 131-140.

20 C. Jubsilp, K. Punson, T. Takeichi and S. Rimdusit, Polym. Degrad. Stab., 2010, 95, 918-924.

21 T. Feng, J. Wang, L. Pan, M. Derradji, N. Ramdani, W. Liu and H. Zhou, Thermochim. Acta, 2016, 633, 1-11.

22 Y. Liu, R. Yin, X. Yu and K. Zhang, Macromol. Chem. Phys., 2019, 220, 1800291. 